\title{
From soap and water, to waterless agents: Update on hand hygiene in health care settings
}

\author{
Joanne Langley MD MSc FRCPC
}

$\mathrm{T}$ he hands of those who provide health care to children palpate, percuss, perform procedures, wipe noses, change diapers, comfort parents and hold children, among many other activities. These multiple physical contacts provide opportunities for microorganisms to travel between the caregiver and the child. Hand washing has traditionally been identified as the most important infection control intervention to prevent disease transmission and is recommended before and after contact with patients, body fluids and dirty material; between dirty and clean procedures on the same patient; before and after performing invasive procedures; and after using the washroom (1). In recent years, a plethora of hand hygiene products, including many with antimicrobial activity, has become available and some are marketed to the general public. In the present note, the various agents available for hand hygiene are reviewed and suggestions for their appropriate use in nonsurgical health care settings are made.

Just like other bodily organs, human skin has a normal physiological state. The function of skin as a barrier is maintained by water content, intercellular lipids, temperature and rates of desquamation (2). Skin normally is colonized by bacteria that can reach counts as high as 1000 colonyforming units $/ \mathrm{cm}^{2}$ near the hands (3). Bacteria are thought to be resident if they are attached to deeper layers of skin, and transient if they colonize superficial layers of skin. Hand hygiene eliminates the transient flora that are acquired by caregivers during direct contact with patients or contaminated environmental surfaces adjacent to a patient. The products available can be categorized into hand washing agents (plain soaps or antiseptic soaps) and handrubs (antiseptic waterless agents) (4).

\section{PLAIN SOAP}

Hand washing with plain soap suspends microorganisms and mechanically removes them by rinsing with water. Plain bar soap, leaf, tissue or liquid preparations are comprised of detergents with surfactant or 'surface-active' activity that holds dirt or transient flora in suspension. Cleaning is due to the physical removal of foreign material or microorganisms, not killing.

\section{ANTIMICROBIAL SOAP}

An antimicrobial soap combines the cleaning action of the physical removal of foreign material with an antiseptic agent that kills microorganisms. The antimicrobial agents (eg, alcohol, chlorhexidine, iodine, triclosan, hexachlorophene) usually have sustained activity on the skin that continues to reduce the number of microbial flora after the hand wash is complete.

\section{WATERLESS AGENTS}

Antiseptic handrubs are waterless agents with disinfectant properties that decrease the number of microorganisms present. The individual applies a small amount (approximately $3 \mathrm{~mL}$ ) to the hands, then rubs the hands together until the agent has dried. An antiseptic handrub does not require the use of exogenous water. Most alcohol-based hand antiseptics contain either isopropanol, ethanol, n-propanolol or a combination of two of these products (4). They are available in varying concentrations, or in combination with a small amount of other antiseptics. Antimicrobial activity is due to their ability to denature proteins. Because these handrubs do not remove organic material, they cannot be used if hands are visibly soiled.

\section{CONSIDERATIONS FOR USE}

The important considerations in evaluating the suitability of a hand hygiene product for use in a clinical setting are its efficacy in preventing the transmission of microorganisms, adverse consequences (odour, skin damage) for health care providers, ease of access for users, affordability (5), and concerns about the induction of resistant bacteria (6). Skin irritation from hand washing (dryness, dermatitis) affects

\footnotetext{
Clinical Trials Research Centre - Infectious Diseases, IWK Health Centre, Halifax, Nova Scotia

Correspondence and reprints: Dr Joanne M Langley, Infection Control Services and the Clinical Trials Research Centre, IWK Health Centre, Halifax, Nova Scotia B3J 3G9. Telephone 902-470-8498, fax 902-470-7217, e-mail joanne.langley@dal.ca
} 
compliance with hand hygiene and increases the ability of pathogenic bacteria to adhere to skin $(5,7)$. Difficult access and the time required to practise hand hygiene limit its implementation. For example, approximately $62 \mathrm{~s}$ are needed to complete a hand wash and, therefore, $16 \mathrm{~h}$ of nursing time per shift could be expended for hand washing in a 12 unit intensive care unit. By contrast, only $4 \mathrm{~h}$ per shift would be used for hand hygiene if a bedside alcohol hand disinfectant were used (5).

Studies of the efficacy of hand hygiene agents have shown that antiseptic agents (antimicrobial soaps or waterless antiseptic handrubs) are significantly more effective in reducing microbial counts on skin than plain soap and water hand washing in reducing skin flora $(4,8-10)$. The Draft Guideline for Hand Hygiene in Healthcare Settings (10) produced by a joint task force of national infection control societies and the Centers for Disease Control and Prevention concluded that alcohol-based handrubs are more effective than washing hands with antimicrobial or nonantimicrobial soap, can be made more accessible, require less time to use and are less prone to cause irritant contact dermatitis (10). In health care settings that involve ambulatory patients who are not at high risk for serious infectious diseases, and in the home, mild plain soaps will likely be sufficient. If the risk of infection is thought to be increased, an antimicrobial hand hygiene agent will reduce the risk of transmission of pathogen organisms. Waterless agents have the additional benefit of not requiring access to water and sinks, ease of use, rapid action and no risk of antimicrobial resistance. Infection control personnel are an invaluable resource when making a choice among the plethora of hand hygiene agents that balance patient safety, health care worker acceptability and affordability.

\section{RECOMMENDATIONS}

- Hand hygiene is an important infection control intervention to prevent the transmission of microorganisms and should be practised before and after patient contact, when hands are visibly dirty, after using the washroom and at other times when hands may be soiled.
- For some ambulatory, low risk patient care contacts, cleansing the hands with a mild, nonantimicrobial cleansing product is sufficient to prevent infectious disease transmission.

- For patient care in areas with high risk patients or before invasive procedures where there will be a health care benefit in decreasing the microbial load on health care worker hands, an antiseptic agent (waterless handrub or antimicrobial soap) should be used for hand hygiene.

- Waterless hand hygiene rubs are a proven alternative to hand washing agents and are preferred in some settings, including when there are time constraints or lack of access to sinks and running water. Visible organic material must be removed for waterless agents to exert their antimicrobial activity.

- Skin emollients should be used to prevent skin damage from frequent hand washing. If skin emollients are used, care must be taken to ensure that specific products do not interfere with the activity of hand antiseptic hand hygiene products.

\section{REFERENCES}

1. American Academy of Pediatrics. Committee on Infectious Diseases and Committee on Practice and Ambulatory Medicine. Infection control in physicians' offices. Pediatrics 2000;105:1361-9.

2. Larson E. Skin hygiene and infection prevention: More of the same or different approaches? Clin Infect Dis 1999;29:1287-94.

3. Selwyn S. Microbiology and ecology of the human skin. Practitioner 2000;224:1059-62.

4. Widmer AF. Replace hand washing with use of a waterless alcohol hand rub? Clin Infect Dis 2000;31:136-43.

5. Boyce JM. Antiseptic technology: Access, affordability, and acceptance. Emerg Infect Dis 2001;7:231-3.

6. Levy SB. Antibacterial household products: Cause for concern. Emerg Infect Dis 2001; 7:512-5.

7. Larson E. Hygiene of the skin: When is clean too clean? Emerg Infect Dis 2001;7:225-30.

8. Pittet D, Boyce J. Hand hygiene and patient care: Pursuing the Semmelweis legacy. Lancet Infect Dis 2001;1:9-20.

9. Hand washing, cleaning, disinfection and sterilization in health care. Can Commun Dis Rep 1998;24(Suppl 8):i-xi,1-57.

10. Boyce J, Pittet D, Hand Hygiene Task Force, Committee HICPA. Draft guideline for Hand Hygiene in Healthcare settings. Atlanta: Centers for Disease Control and Prevention, 2001.

\section{CANADIAN PAEDIATRIC SOCIETY INFECTIOUS DISEASES AND IMMUNIZATION COMMITTEE}

Members: Drs Upton Allen, The Hospital for Sick Children, Toronto, Ontario; H Dele Davies, Division of Infectious Diseases, Alberta Children's Hospital, Calgary, Alberta; Joanne Embree, The University of Manitoba, Winnipeg, Manitoba, (chair); Joanne Langley, Department of Pediatrics, IWK Health Centre, Halifax, Nova Scotia; Mireille Lemay, Department of Infectious Diseases, Sainte-Justine Hospital, Montreal, Quebec; Gary Pekeles, The Montreal Children's Hospital, Montreal, Quebec (director responsible)

Consultants: Drs Noni MacDonald, Faculty of Medicine, Dalhousie University, Halifax, Nova Scotia; Victor Marchessault, Cumberland, Ontario Liaisons: Drs Scott Halperin, Department of Pediatrics, IWK Health Centre, Halifax, Nova Scotia (IMPACT); Susan King, Division of Infectious Diseases, The Hospital for Sick Children, Toronto, Ontario (Canadian Paediatric AIDS Research Group); Monique Landry, Direction de la santé publique de Laval, Laval, Quebec (Public Health); Larry Pickering, Centre for Pediatric Research, Norfolk, Virginia, USA (American Academy of Pediatrics, Committee on Infectious Diseases)

Principal author: Dr Joanne Langley, Halifax, Nova Scotia

The recommendations in this note do not indicate an exclusive course of treatment or procedure to be followed. Variations, taking into account individual circumstances, may be appropriate. This article also appears in Paediatr Child Health 2002;7(8):511-512. 


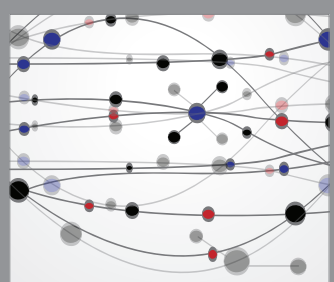

The Scientific World Journal
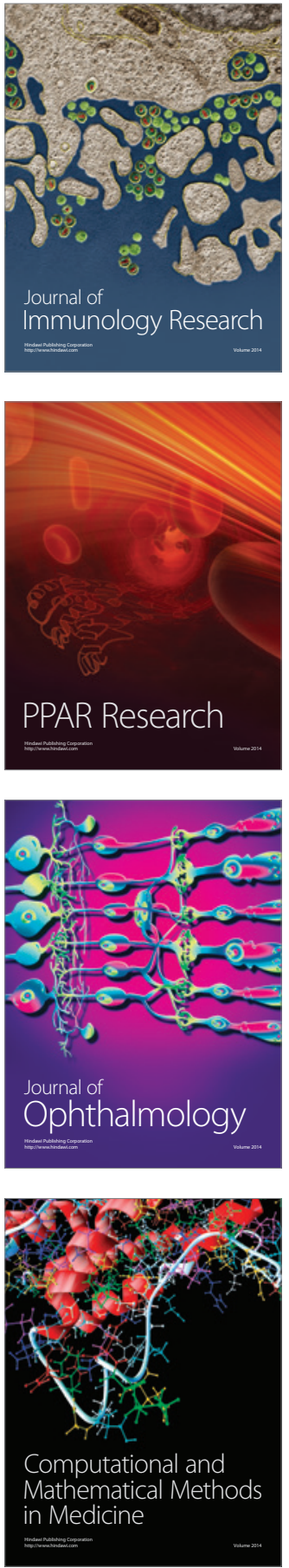

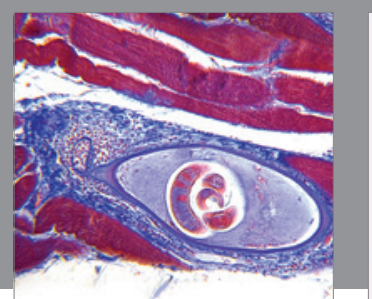

Gastroenterology Research and Practice

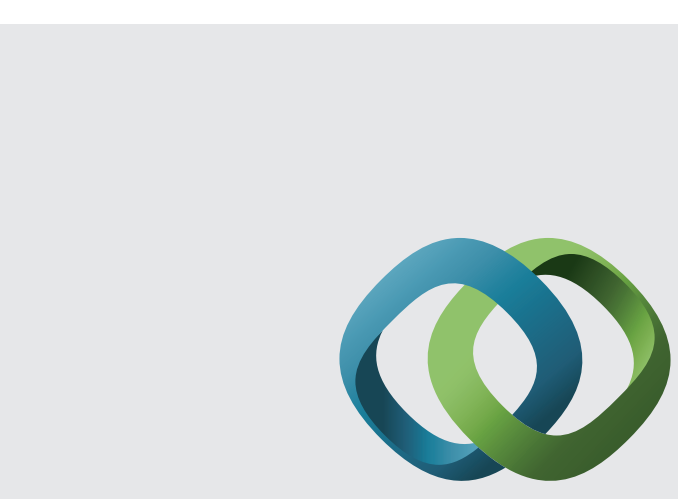

\section{Hindawi}

Submit your manuscripts at

http://www.hindawi.com
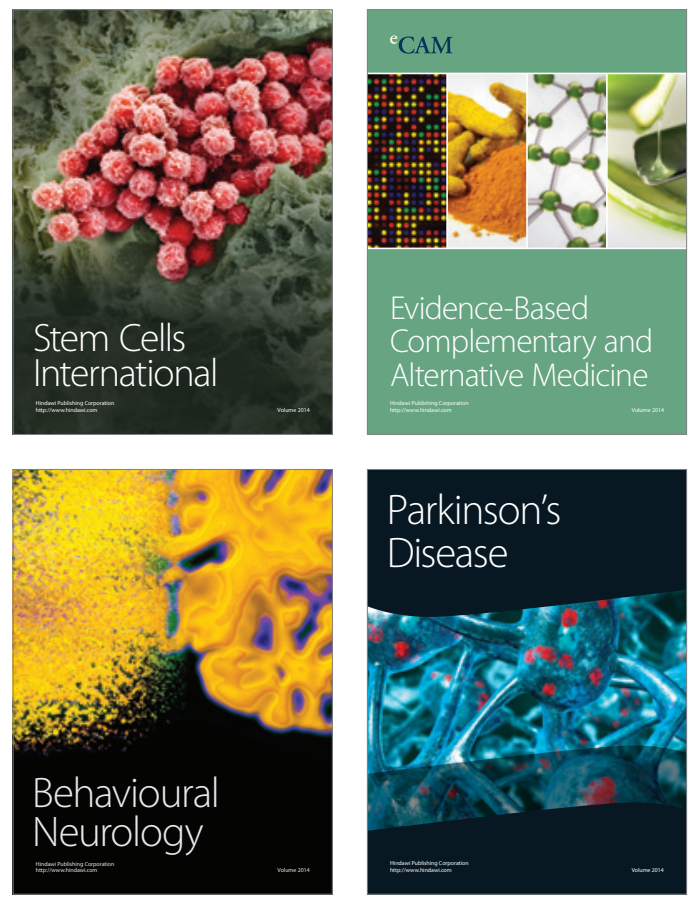
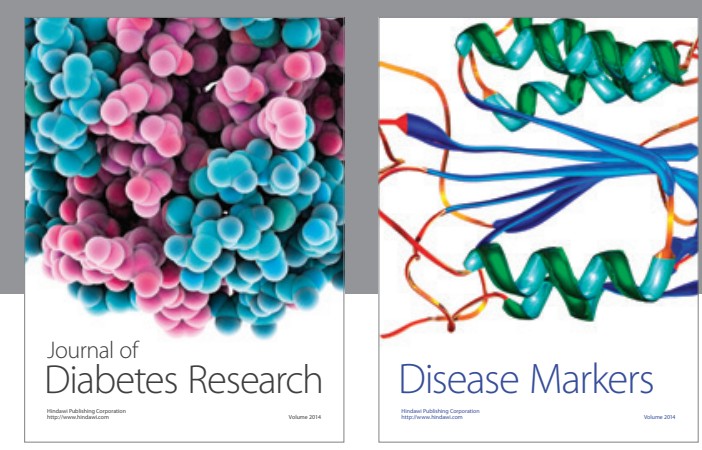

Disease Markers
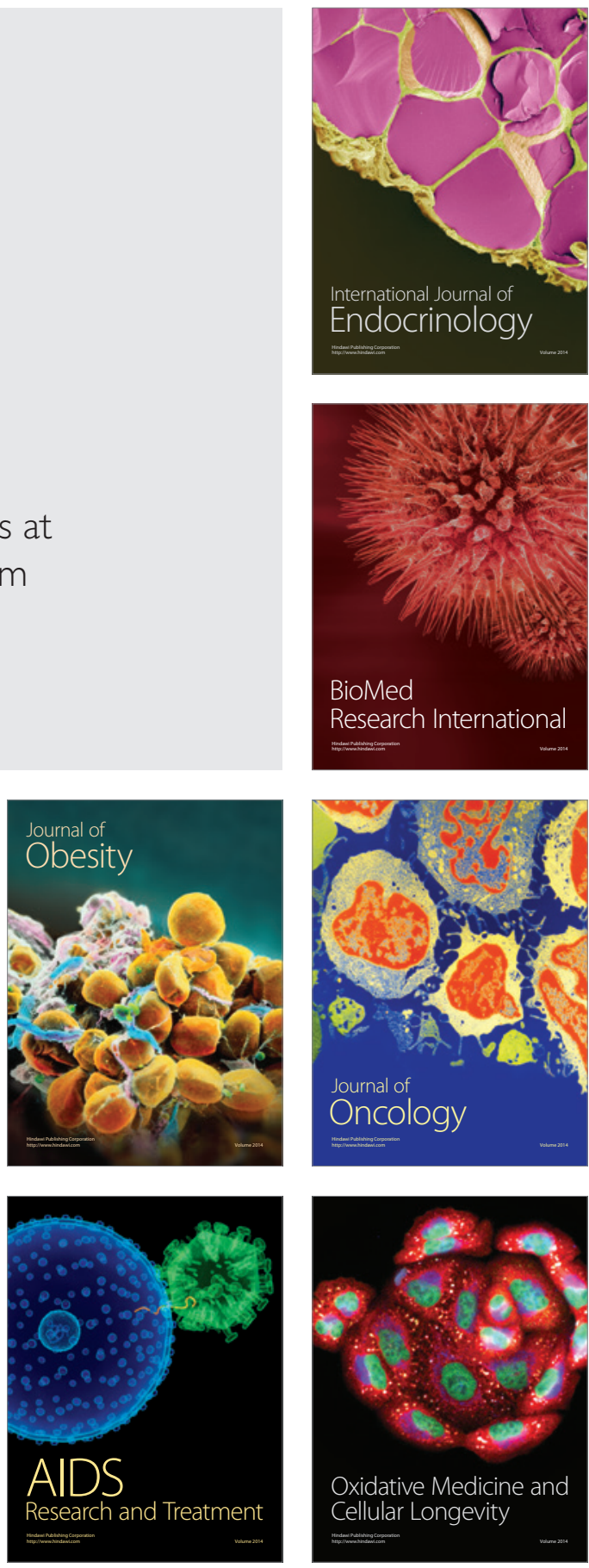